\title{
Correction to: Vascular Tissue Engineering: Pathological Considerations, Mechanisms, and Translational Implications
}

Frederick J. Schoen, Emanuela S. Fioretta, Anna Mallone, Anthal I. P. M. Smits, Leda Klouda, and Carlijn V. C. Bouten

\section{Correction to:}

“Vascular Tissue Engineering: Pathological Considerations, Mechanisms, and Translational Implications" in B. H. Walpoth et al. (eds.), Tissue-Engineered Vascular Grafts, Reference Series in Biomedical Engineering, https://doi.org/10.1007/978-3-030-05336-9_15

Owing to an unfortunate oversight during the production process, chapter "Vascular Tissue Engineering: Pathological Considerations, Mechanisms, and Translational Implications" was initially published with incomplete authorship information. This has now been corrected. 